\title{
Multivariate Analysis of Dietary Patterns in 939 Swiss Adults: Sociodemographic Parameters and Alcohol Consumption Profiles
}

\author{
MARLANNE GEX-FABRY, LUC RAYMOND AND OLVIER JEANNERET
}

\begin{abstract}
Gex-Fabry M (Department of Social and Preventive Medicine, University of Geneve, Switzerland), Raymond $L$ and Jeanneret O. Multiveriate enalysis of dietary petterns in 939 Swiss adults: Sociodemographic parameters end alcohol consumption profiles. Intemetional Joumal of Epidemiology 1988, 17: 548-555

A dietary survey of 939 Swise adults, rendomly selected from the population of Geneva and tes surrounding communities, was performed according to the history method. A factor analysis, using averege woekly intakes for 33 food variables, reveals three principal components of the dlet: setiating capacity, healthfulness and culinary complexity. These characteristics, together with the energy content of the diet, were analysed for differences according to sex, age, relative welght index, birthplace, marital status and occupation. All of these sociodemographic veriables influence some dimension of dietary habits. Alcohol consumption is positively associated with satiating, protein rich diets, but energy intake from foods does not significatively differ betwoen various groups of abstainers and drinkers. Although the energy contribution of alcoholic bevereges is globally additive, we suggest thet cultural and societal norms may modulate the relationship of alcohol and diet.
\end{abstract}

Food functions as a supply of energy as well as a complex behavioural code to create personal eating patterns. The energy requirement for an individual depends primarily on his basal metabolic rate, as determined by age, body size and weight, and also varies with his work- or leisure-associated level of physical activity. Additional adjustments may be needed to account for climatic variations. ${ }^{1}$ Given these requirements and available food resources, the process of food selection depends on many factors. Physiological controls include intolerance and sensitivity to particular substances. Sensory characteristics, such as taste, visual appearance and texture, are also elements contributing to food preference or aversion. In addition, social and economic factors lead to evaluation of foods with respect to cost, convenience, prestige and healthfulness, among other criteria. ${ }^{2}$

The influence of alcohol on diet may be considered from different points of view. It contributes to an individual's supply of energy, although the utilization of

Department of Social and Preventive Medicine. Unjversity of Geneva, Switzerland.

Reprint requests: Professor Olivier Jeanneret, Institut de MEdecine Sociale et Prtventive, 27 quai Charles-Page, 1205 Oentve, Switzertand. calories derived from ethanol may be partly inefficient. $^{3}$ Alcohol interferes with food absorption: impaired digestion and metabolism of nutrients have been documented in alcoholic patients." It also affects the release of neurotransmitters which play important roles in appetite and satiety controls. ${ }^{5,6}$ Finally, sociocultural factors govern the association of specific drinking habits with particular dietary practices. Whether alcohol deserves to be considered as a dietary element in the conventional sense remains a matter of debate.

Observations relating alcohol to diet generally differ depending on whether alcoholic or normal subjects are studied. Nutritional deficiencies in alcoholic patients have often been reported. Calories derived from ethanol tend to replace food calories and may represent important proportions of the total daily energy intake. $^{78}$ In the general population, the sociodemographic determinants of drinking habits on the one hand ${ }^{9.10}$ and eating patterns on the other ${ }^{11,12}$ have been investigated. The interference of alcohol and diet raised less interest. Studies generally agree that energy derived from alcohol adds to the normal diet rather than replaces food calories. ${ }^{13-15}$ This picture is far from complete however, since alcohol consumption may not 
only affect total energy balance but may also influence the dynamic process of food selection.

The purpose of the present study is twofold. Firstly, it aims at a better understanding of eating patterns among adult residents of Geneva (Switzerland) and identification of some of their many determinants. Secondly, it focuses on the relationship of eating and drinking habits and the factors which influence the part assumed by alcohol in the diet. Although necessary for measuring the nutritional status of a community, conventional evaluation of foods in terms of major nutriento-fat, proteins, carbohydrates-has little to offer in terms of establishing individual dietary practices. Our multivariate approach emphasizes more qualitative dimensions of the diet referred to as 'satiating capacity', 'healthfulness' and 'culinary complexity'. Its energy content is included in the analysis in order to allow for comparisons with other studies.

\section{METHODS}

Subjects

A detailed description of the sampling procedure, response rate and representativeness of the sample has been published. ${ }^{16}$ Briefly, a $61 \%$ participation rate was obtained from a random sample of the adult population of Geneva and immediate surroundings (Canton of Geneva, population ca.350 000). The stratification design led to overrepresentation of the older age

TAuls 1 Soctodemogrephic characteristics of the sample population

\begin{tabular}{lcc}
\hline \multicolumn{1}{c}{ Characterbtic } & Men & Women \\
\hline Age & 57 & 51 \\
$19-34$ years & 84 & 68 \\
$35-44$ & 90 & 71 \\
$45-54$ & 106 & 53 \\
S5-64 & 110 & 75 \\
$65-74$ & 109 & 65 \\
$>75$ & & \\
Obesity inder & 62 & 44 \\
thin & 363 & 272 \\
nomal & 131 & 67 \\
obese & & \\
Birth place & 339 & 203 \\
French Switzerland & 62 & 43 \\
German Switzerland & 46 & 31 \\
France & 55 & 45 \\
Mediternanean countries & 54 & 61 \\
other countries & & \\
Maritul status & 28 & 54 \\
single & 444 & 231 \\
married & 52 & 80 \\
widowed & 32 & 18 \\
divorced or weparated & 556 & 383 \\
\hline Total number of subjects & & \\
\hline & & \\
\hline
\end{tabular}

groups, with $38 \%$ of the subjects being 65 years or older, as compared to $13 \%$ in the general Geneva population. Of the 960 participants, 21 were excluded because of incomplete data. The distribution of the final population by sex, age, obesity index, marital status and place of birth is given in Table 1 . The body mass index $\left(\mathrm{kg} / \mathrm{m}^{2}\right)$ is used to separate thin, normal and fat subjects, depending on whether they are below, within or above the desirable weight range defined by the World Health Organization. ${ }^{1}$ The cultural background of Geneva residents was assessed through their place of birth summarized in five categories: French speaking and German speaking parts of Switzerland, France, Mediterranean countries, and other countries. In addition, for each male subject, the current or most recent occupation preceding retirement was recorded and classified into one of the following 13 categories: unskilled worker, skilled worker, foreman, craftsman, self-employed, farmer or farmworker, clerk, chief clerk, minor executive, executive, senior executive, professional and general manager. The number of subjects exceeds 25 in each occupational group apart from foremen (18) and farmers or farmworkers (10).

\section{Dietary Data}

The Geneva dietary survey was based on the history method, previously described and validated by Cubeau and Pequignot. ${ }^{17}$ Interviews were conducted between 1977 and 1982 by two trained dieticians. The amount and frequency of intake over a two-week period were recorded for 109 foods and beverages, for each meal and intermediate snacks. Questions referring to alcoholic beverages were integrated into the interview: this method to assess alcohol consumption is widely accepted in European latin countries. ${ }^{18}$ The average intakes aimed to be representative of usual diets and to account for seasonal variations. ${ }^{17}$ The energy content of the diet was estimated from a food composition table adapted to the Geneva questionnaire. ${ }^{16}$

In a first attempt to reduce the complexity of the data, some of the initial food items were grouped together (eg whole milk and skimmed milk), while some others were omitted because they were considered as minor components of everyday diets (e.g. game, candy). The final 33 food variables are listed in Table 2, together with mean values and standard deviations in grams per week. The items referring to alcoholic beverages were converted to grams of ethanol per day. Contributions were then added and average daily alcohol intake was used to classify subjects into five groups, from abstainers to heavy drinkers. 
Statistical Analysis

A principal components analysis was first performed on the correlation matrix for the $\mathbf{3 3}$ food variables and the 939 subjects who completed the interview (procedure FACTOR of the SPSS-X statistical package). ${ }^{19}$ Factor scores were calculated for each individual and used to project centres of gravity for particular groups

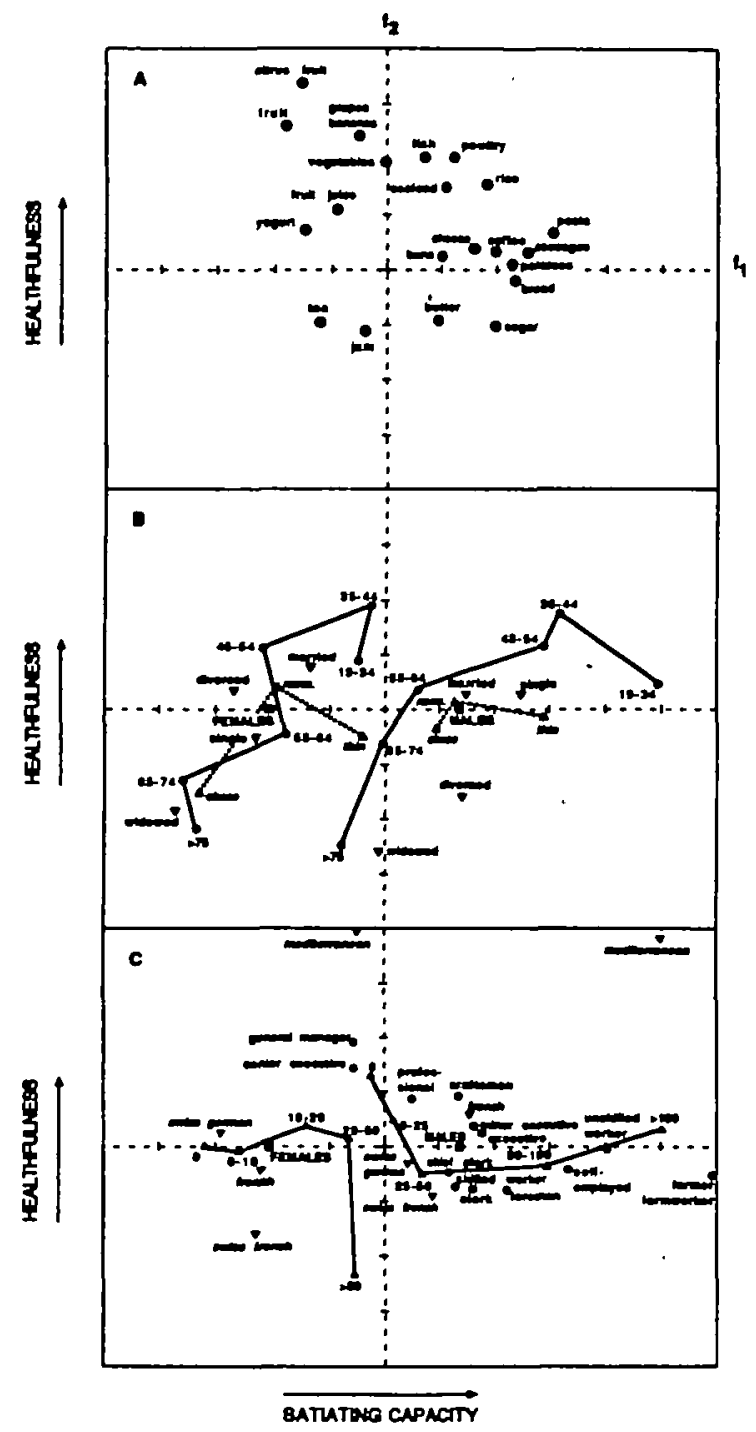

Froune 1: Distribution of foods and population groups according to the sotianting copacily and health fulness of the diet.

The ares are the first and second factors resulting from principal components analyxis. Pent A: dintribution of foods, for loadings langer than 0.2. Part B: distribution of subject occonding 10 sex (D), age group (O), aberity index ( $\Delta$ ) and marital statu $(\nabla)$. Part $C$ : dirtribution of subjects according to bith plece $(\nabla)$, accupational group $(O$, men only) and average alcothol insake in grans per day $(\Delta)$. Males and females are srosed separasely.
TABLE 2 Lis of food veriables (g/week)

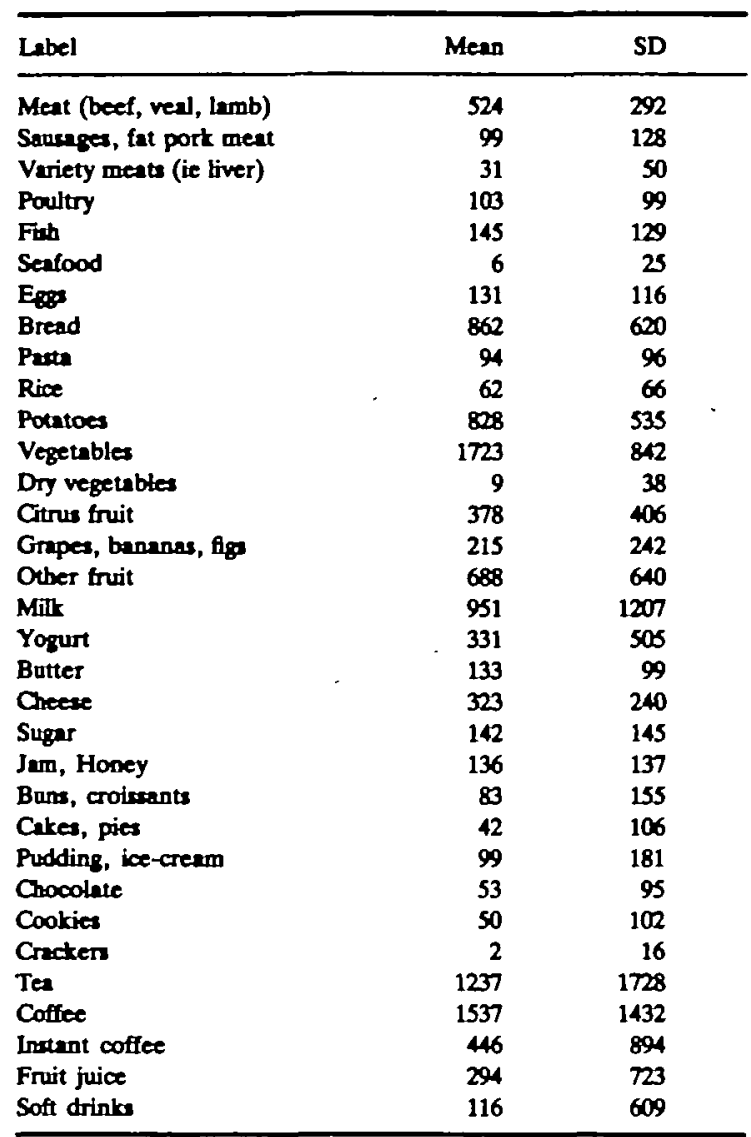

of subjects on the factor axes. Analysis of covariance (procedure ANOVA in SPSS-X) was subsequently used to confirm the revealed patterns and remove possible confusion by taking the various sociodemographic variables simultaneously. The principal components were considered as dependent variables, with age and relative weight index as covariates, and marital status, place of birth, occupational group and alcohol consumption level as factors. The average daily energy intake, excluding alcohol, was submitted to the same analysis of covariance design.

\section{RESULTS}

Figures 1A and $2 A$ illustrate the distribution of food items along the factor axes. The first three components were found to account for 7.6,6.2 and 5.7\% of the total variation respectively. Higher order factors contributed to less that $5 \%$ each and were neglected for sake of clarity. The three axes represented thus accounted for $19.5 \%$ of the inter-individual variability; this relatively small proportion reflects the multidimensional 
nature of eating patterns. Attribution of provisional meaning to the principal components may nevertheless be attempted. The majority of variables (23 among 33) are positively correlated to the first axis. Main contributions are from heavy and basic foods like pasta, potatoes, bread, fat pork meat and sausages, as opposed to light foods, such as fruit, yogurt and tea. On a preliminary basis, one may thus consider the main component as an index of the satiating capacity of an individual's food intake. The second component may be associated with the healthfulness of the diet. It is highly correlated with the amounts of fruit, vegetables, fish, seafood and poultry. These foods are generally bought fresh. They are believed to be vitamin-rich and to promote physical well-being. The third component opposes seafood, poultry and eggs to the majority of the other food items. Maximum positive loadings from jam, butter and cookies suggest that it may reflect a decreasing complexity of the diet, opposing vegetarian and snack types of food to protein-rich dishes which often require more sophisticated preparation.

Since the majority of population studies quantitate the diet in terms of its energy content, the question of how this measurement would relate to the principal components was considered. Some insight is given by correlation coefficients between energy intake and the factor axes: values of $0.65,0.21$ and 0.57 are found for components 1,2 and 3 respectively $(p<0.001)$. Assuming that the smallest coefficient is negligible when compared to the others, an hypothetical energy axis would be located in the first quadrant of Figure 2. As illustrated, energy rich foods include butter, sugar and bread as well as pasta and jam.

A first insight into the average behaviour of various population groups is found in Figures $1 B, C$ and 2B, C, in which sociodemographic parameters are considered independently from each other and separately for males and females. Diagrams include alcohol consumption profiles : different intake ranges reflect different average consumption levels for men and women (43 and 13 grams of ethanol per day respectively). The proportion of non-drinkers is also larger among women than among men ( $19 \%$ versus $5 \%$ ). Since some correlations between sociodemographic factors are expected, the results in Figures 1 and 2 are presented together with analyses of covariance tables. Mean values for each population subgroup, expressed as deviations from the grand mean, and adjusted for age, body mass index and the other categorical variables, are reported in Table 3. Effects of sex, age, obesity, marital status, place of birth, occupational group and drinking status are described below.

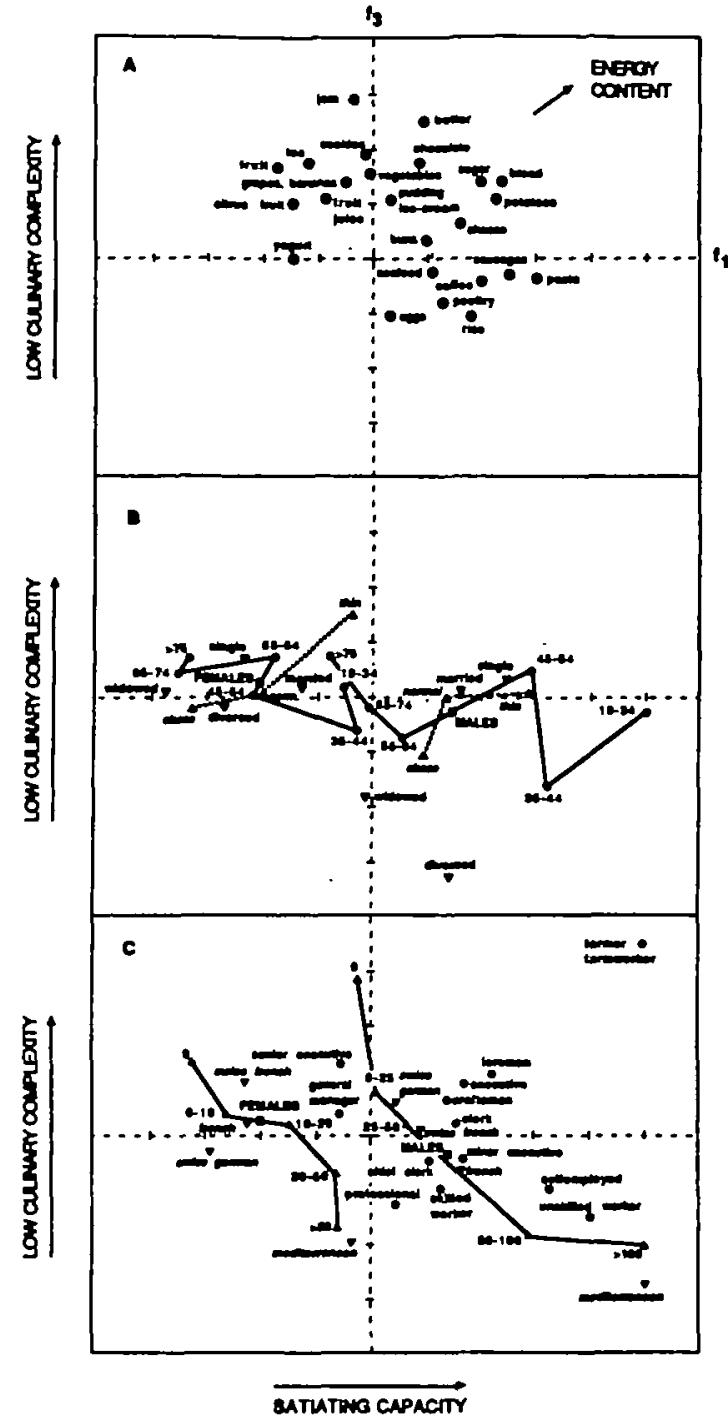

Foune 2: Dirtribution of foods and population graups according to the satiating capacily and aulinary complexity of the diat.

The ares are the first and third foctors resulting from princtoal componerts whatyst. Part A: distribution of foods, for loadings larger than 0.2. Part B: distribution of subjects according to sex (D), age grosp

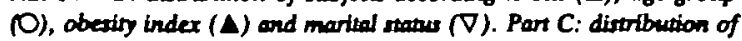
mubjects eccording to birth plece (V), accupational group (O, men

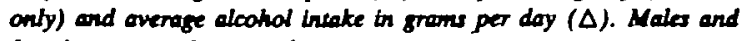
fomales are stated seperately.

$\operatorname{Sex}$

Figures $1 B$ and 2B indicate that the major difference between males and females relates to the satiating capacity of their diet: women ingest smaller amounts of rich and heavy foods. Their daily energy intake is, on the average, $1268 \mathrm{~kJ}$ (303 kcal) lower than men's. No difference affects the quality of the diet, as assessed 
INTERNATIONAL JOURNAL OF EPIDEMTOLOGY

TAsus 3 Anatysts of covariance

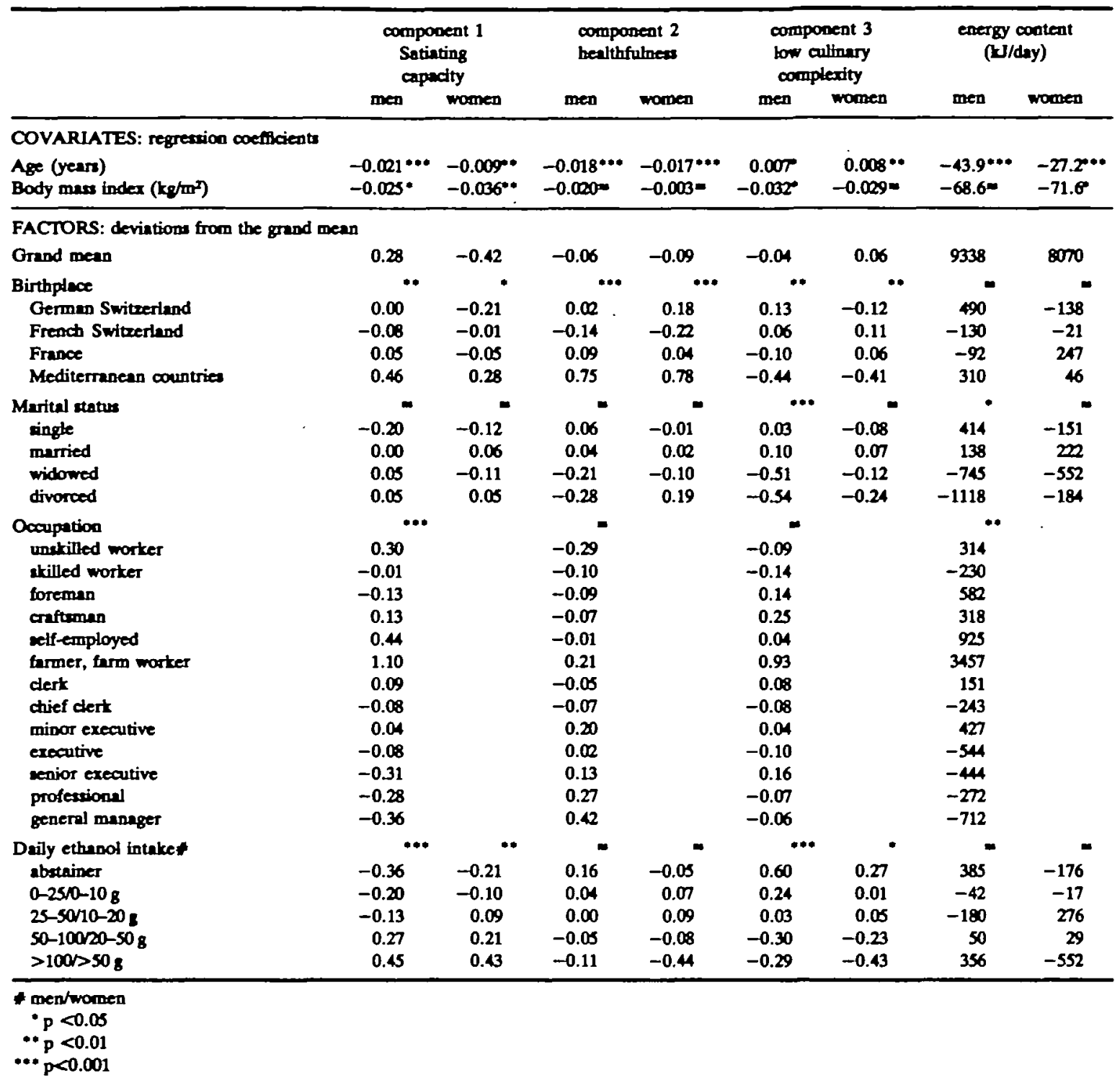

from its apparent healthfulness and culinary complexity.

Age

Age affects dietary habits in different ways. From Figure 1B and the negative regression coefficients in Table 3, it appears that age is associated with reduced intake of most food items, including potatoes, bread, pasta, fish, poultry, fruit and vegetables. A concomitant decrease of the energy content of the diet is observed. Figures 1B and 2B further suggest a possible shift from protein-rich dishes which often require long or sophisticated preparations (poultry, fish, seafood) to snack foods that do not require cooking (butter and jam, tea and cookies). Interestingly, an inverse trend is observed when comparing the younger age groups: the presence of vitamin-rich elements and the apparent complexity of the diet increase with age.

\section{Relative Weight Index}

The energy requirement for a given type of activity depends on body size.' A heavy subject expends more calories and is thus expected to have higher dietary intakes, providing weight is stabilized. The opposite 
effect is found in Table 3. The energy content of the diet decreases with the obesity index, even though the effect is slightly above the $5 \%$ significance level for men. From Figure 1B, it can be seen that subjects below the desirable weight range seem to consume larger amounts of 'filling' foods. A regression coefficient remains statistically significant when correction is made for age (Table 3 ). Figure $2 \mathrm{~B}$ suggests that obese people have, on the average, protein rich rather than vegetarian types of diets.

\section{Marital Status}

Figures $1 B$ and $2 B$ suggest a possible influence of marital status on dietary patterns. However, the associated analyses of covariance reveal that some of the observed differences are more likely to be attributed to age. After adjustment for age, the apparent category effect in Figure 1B disappears. Nearly perfect correspondence is found between groups of widowed men and women and the respective older age groups. However, some differences remain significant. Widowed and divorced men tend to have protein rich diets but reduced intakes of fruit and vegetables, when compared to their married counterparts. Smaller amounts of jam, butter, cookies lead to the hypothesis that they may prefer full meals to snacks. Their energy intake is also lower than for married and single subjects.

Place of Birth

The diet of people from the Mediterranean countries significantly differs from that of subjects born in Switzerland or France. It is characterized at once by abundancy of satiating and vitamin-rich foods and by culinary complexity, with fish, seafood and poultry dishes often prepared. No significant differences are found with respect to food-derived energy.

\section{Occupational Group}

The analysis of Figure $1 \mathrm{C}$ indicates that large consumers of rich and heavy foods are found mainly among farmers and farm workers, unskilled workers and selfemployed workers. Larger quantities of inexpensive foods such as potatoes, pasta, bread and pork meat characterize their diet. Senior executives, professionals and general managers eat, on average, greater amounts of fish, vegetables and fresh fruit. Significant differences between groups similarly affect the caloric content of the diet: subjects in the lower socioeconomic categories tend to have higher energy intakes (Table 3). As far as healthfulness and complexity of the diet are concerned, the hypothesis of equal mean values for the 13 groups cannot be rejected after corrections are made for the other sociodemographic variables.

\section{Drinking Status}

Confirmation of the raw patterns in Figures $1 \mathrm{C}$ and $2 \mathrm{C}$ is obtained from the analyses of covariance (Table 3). Alcohol intake is positively associated with rich diets. Moreover, heavy drinkers tend to have protein rich rather than vegetarian types of diets, the latter being more frequent among abstainers. When analysing energy content, however, the hypothesis of equal mean values cannot be rejected, either for men or women. The contribution of alcohol thus seems to be additive to food derived energy. As illustrated in Figure 2C, alcohol consumption profiles are roughly perpendicular to the postulated energy axis. Interestingly, average energy intakes for either abstainers or heavy male drinkers exceed that for categories of small and moderate drinkers. The opposite trend is found for women.

\section{DISCUSSION}

This analysis explores some dimensions of dietary patterns in the Geneva community in relation to a number of sociodemographic determinants. They all influence some aspect of the diet, either its energy content or some more qualitative dimensions. These underlying, not directly observable dimensions summarize sets of relationships between a great number of foods entering the usual diet. The labels satiating capacity, healthfulness and culinary complexity are obviously crude attributes for complex behavioural variables, but nevertheless provide valuable guidelines for discussion.

Besides the often reported sex difference in the energy content of the diet, ${ }^{12,13}$ differences between male and female behaviour toward food may be postulated. The general picture in Figure 2B, together with the observation that Swiss women eat fruit, salad and yogurt more frequently but sausages and cheese less often than $\operatorname{men}^{20}$ is in keeping with the sociological hypothesis of food items having either male or female attributes. $^{21}$

Decreasing food intakes with increasing age may be attributed to decreased energy requirements, which are in turn associated with changes in body composition and physical activity. ${ }^{1}$ The concomitant change in the apparent complexity of the diet parallels changes in its nutritional balance. The proportion of calories derived from proteins and lipids decreases while that due to carbohydrates increases. ${ }^{16}$ Although this may be associated with economic factors, and possibly with physiological and psychosociological problems related 
to ageing, a generation effect cannot be excluded. For example, important changes have affected the food supply and economic status of the European population over the last $\mathbf{5 0}$ years. The importance of lipids in the French diet has gradually increased at the expense of carbohydrates. 2 The apparently more healthy diet of the 35 to 44 year old subjects has to be pointed out. Young adults may emphasize the importance of wellbalanced diets for multiple reasons, including presence of children at home, efforts to keep a slim figure and awareness of the nutritional value of foods.

Though contrasting with common belief and routine clinical observations, our results are in agreement with other cross-sectional studies which demonstrate reduced energy intake associated with obesity. ${ }^{23}$ Possible explanations include underestimation of ingested quantities, decreased physical activity and reduced thermogenic response to food among overweight subjects. ${ }^{24}$ Relative contributions of the major nutrients are not affected by the relative weight of the subjects. ${ }^{25}$

A distinctive eating pattern among widowed and divorced men was also noted. Their diet, based on protein-rich dishes rather than snacks, has a rather low energy content. One may hypothesize that this group may skip light meals such as brealfast and may eat outside the home more frequently than married subjects of the same age. Interestingly, the absence of a spouse induces a dietary change for men only, confirming that women play the central role in establishing family dietary habits.

An analysis of the cultural determinants of dietary habits is beyond the scope and purpose of the present study. However, a parallel may be drawn between the satiating and protein-rich diet of Geneva residents born in Mediterranean countries and French observations in groups of immigrant workers from Spain and Portugal. ${ }^{20}$ Abundancy of food and especially of meat is interpreted as a sign of wealth. Traditionally, two full meals are served daily, while snacks often replace dinner in Swiss families. Only $18 \%$ of Swiss people report eating meat for dinner, while $55 \%$ report eating bread and $26 \%$ cheese. ${ }^{20}$

The association of rich and satiating diets with occupations involving intense physical activity is not surprising. Energy requirements clearly increase with the intensity and duration of exertion. ${ }^{1}$ On the other hand, our results qualitatively agree with French studies, pointing to a social hierarchy of foods in which intakes of 'light' and 'heavy' foods respectively increase and decrease with increasing socioeconomic status."

The relationship of alcohol consumption and diet requires particular attention. Overall ethanol intake obviously gives a crude image of drinking habits. The kind of beverage, the time of the day, the frequency of intake and the quantity imbibed per occasion are likely. parameters of the relation of alcohol and dietary habits. In our subjects, on the average, wine represented $69 \%$ of the ethanol intake, of which $88 \%$ was consumed at lunch or dinner time. The positive association of alcohol intake with protein-rich, satiating diets may thus be interpreted with respect to the cultural regulation of alcohol use. ${ }^{27}$ In French speaking parts of Switzerland, as in France, the nutritional use of wine is widespread. It is traditionally associated with meals and its intake level may parallel the amount of ingested foods.

The role of alcohol versus food derived energy in the Geneva community corroborates the results of several previous studies: ${ }^{13,15}$ Globally, ethanol adds to the diet rather than substitutes for food, for both men and women. Inefficient disposal of calories has been postulated as a consequence of alcohol drinking. Possible mechanisms include impaired absorption of foods 4 and activation of an energy wasteful metabolic pathway by ethanol. ${ }^{3}$

The detailed analysis of alcohol consumption profiles with respect to food derived energy reveals intriguing differences between men and women. Males who drink moderately have lower energy intakes than either abstainers or heavy drinkers, while the opposite trend is found for females. Among heavy drinkers (>50g per day) representing $4 \%$ of our female population, low energy content of the diet and reduced intake of vitamin-rich foods were noted. A previous study reports that alcohol tends to replace food calories to a larger extent among female drinkers than among males. ${ }^{23}$ The behaviour of heavy female drinkers with respect to alcohol and diet is thus similar to that of male alcoholics, for whom alcohol is a substitute for food. ${ }^{7.8}$ Some insight may be provided by the common clinical experience that women have a greater susceptibility to the pathological effects of alcohol. ${ }^{20}$ Alternatively, a greater awareness of the energy content of food and alcohol might be invoked.

These preliminary observations suggest that the shape of alcohol consumption profiles with respect to the principal components of the diet may not only depend on gender but on various social and cultural factors. A previous publication revealed that the contribution of alcohol-derived calories to the total daily energy intake may be partly culture specific. ${ }^{30}$ Age, marital status, and sociocconomic status are similarly expected to influence how much, where, when and why a person drinks. Further work is needed to identify the 
factors which control and modify the nature of the relationships between eating and drinking habits.

\section{ACKNOWLEDGEMENTS}

This research was made possible by grants from the Swiss Nutrition Foundation and the Swiss Foundation for Alcohol Research. Data collection was subsidized by the Swiss National Fund for Scientific Research (FNRS, No. 3.809.0.79), the Swiss Cancer League (FOR.160.AK.79), and the National Institute on Alcohol Abuse and Alcoholism (USA).

The authors would like to acknowledge the assistance of dieticians Mrs $\mathrm{V}$ Hollenweger, Mrs M-C Zurkirch-Conti, and Mrs M Cudre-Mauroux in collecting the data. We are also grateful to Dr Eric Brenner for his valuable comments and to Mrs A Primault for typing the manuscript.

\section{REFERENCES}

1 World Health Organtzation. Enersy and protein requirements. WHO Tectnical Report Series No 724, Geneva, 1985.

${ }^{2}$ Messer E. Sociocultural aspects of nutrient intuke and behovional response to nutrition. In: Galler J R (ed) Nurrition and behavior. Plenum Press, New York, 1984; 417-71.

${ }^{3}$ Pirota R C. Lieber C S. Hypothesis: energy wastage in alcoholiem and drug abure, poscible rote of bepatic micro:onal enxymes. Am J Clin Nutr 1976; 25: 90-3.

4 Morgan M Y. Alcohol and nutrition. Br Med Bull 1982; 38: 21-9.

' Hoebel B G. Brain neurotransmitters in food and drug rewerd. Am J Cin Nutr 1985; 12: 1133-50.

- de Witte P. Prychobiotogie de l'alcoolisme. HCEIA Bull 1985; 3: $372-83$.

'Hurt R D, Higgins J A, Netwon R A, Morse R M, Dictwon E R. Nutritional status of a group of alcabolics before and after admission to an aloobotiam treatment unit. Am J Cin Nutr 1981; 34: 386-92.

- Bunout D, Gattas V, Iturriaga H, Perez C, Peredn T, Ugarte G. Nutritional status of alooholic patients: its poscible relationahip to alcoholic liver damage. Am J Clin Nutr 1983; 38: 469 73.

- Harford T C. Contextual drinking patterms among men and women. In: Seixes F A (ed) Currents in alcoholism vol 4. Pyychiatric, pryctrabogical, nocial and epidemiological studies. Grune and Stratton, New Yort, 1978; 287-96.

${ }^{10}$ Edward A M, Schort M A, Harbure E, Moll P P, Burns T L, Ozgoren $F$. Sources of variability in quantitative level of alootrol use in a total community: wociodemographic and poychowocial correintes. Int J Epidemiol 1986; 15: 82-90.

"Grignon C, Grignos C. Styles d'alimentation et golts populaires. Rev Franc Soctal 1980; 31: 531-69.

a Binghum S, McNeil N I, Cummings J $\mathrm{H}$. The diet of individuals: a ctudy of a randomly-chosen cross section of British adults in a Cambridgeshire village. Br J Nur 1981; 45: 23-35.

U Jones B R, Barrett-Connor E, Criqui M H, Holdbrook M J. A community study of calorie and nutrient intuke in drinken and non-drinkers of alcobol. Am J Cln Nutr 1982; 35: 135-9.

4 Fisher M, Gordon T. The relatton of drinking and smoking habits to diet: the lipid research dinia previlence atudy. Am J Clin Nutr 1985; 41: 623-30.

is Windhem CT, Wyse B W, Hansen R G. Alcohol consumption and nutrient density of diets in the nationwide food consumption nurvey. J Am Diet Aswoc 1983; 82: 36473.

* Morabia A, Raymond L, Hollenweger V, Zurtirch M C, Rieben A. Variation de la ration autritionnelle velon te sexe et l'age d'spres un questionnaire alimentaire quantitatif. Rev Eptdemiol Sarte Publique 1987; 35: 102-14.

"Cubeau J, Ptquignot G. La technique du queationnaire alimentaire quantitutif utilise par la section nutrition de I'NSERM. Rev Epidtmiol Sante Publique 19:0; 28: 367-72.

L Tuyns A J, Estive J, Raymond L, Berrino F, Benhamon E ex al. Cancer of the larynxhypopharynx, tobecco and atoothol. Int J Cancer 1988; 41: 483-91.

" SPSS- $X$ urer's guide. MoGraw-Hill, New Yort, 1983.

20 Ritzel G. Verzehrsewohnbeiten von Grundnahrungemitteln in Haushaltungen und ihre Bedeutung. In: Aebi $H$, Blumentabl A, Boturen-Hoerni $M$ at al. (ads) Zweiter Schweizerischer Emochrungsbericht. Bern, Hans Huber Verlag 1984; 30-57.

21 Bourtieu P. La dirrinction. Paris, Minuit 1979.

$n$ Pequignof G, Serville Y, Cubeau J, Guilloud-Batailte $M$ et $M$, Guggenbuht-Pequignot F. L consommation alimentaire des franciab en fonction de la taille des aropomerations, refiet de l'evolution longitudinale. Rev Epidéniol Sante Publique 1990; 28: $169-83$.

$\checkmark$ Krombout D. Energy and macronutrient intuke in lean and obese middle aged men (the Zutphen atudy). Am J Clin Nutr 1993; 37: 295-99.

2 Swaminathan R, King R F O J, Holmfield J, Siwek R A, Baker M, Wales J K. Thermic effect of feeding carbohydrate, fat, protein and mixed meal in lean and obese subjects. Am J CII Nut 1985; 12: 177-81.

r Morabia A, Raymond L, Rieben A. Facteurs de rivques alimentuires associts i l'oberite: surexposition masculine? Med Soc Prtv 1985; 30: 231-2.

× Pttonnet C. Habitudes alimentaires et scaulturation. Le groupe familial 1983; 99. 60-4.

27 Makela K. The uses of atcobol and their cultural regulation. Acta Sociol 1983; 26: 21-31.

a Gruchiow H W, Sobocinski K A, Barborikt J J, Scheller J G. Aloohol consumption, nutrient intake and relative body weight among US adults. Am J Clin Nutr 1985; 12: 289-95.

20 Tuyns A J, Ptquignot G. Greater risk of ascitic cirrtosis in femsles in relation to alcobol consumption. Int J Epidemiol 1984; 13: 53-7.

${ }^{x}$ Gex-Fabry M, Geisabuhler P, Raymond L. Contribution de l'akeool l l'alimentution: adtition ou substitution selon l'origine culturelle. Med Soc Prev 1986; 31: 231-3.

(Revised version received October 1987) 